\title{
ОРГАНИЗАЦИЯ И РЕЗУЛЬТАТЫ ИССЛЕДОВАНИЯ УРОВНЯ РАЗВИТИЯ МЕЛКОЙ МОТОРИКИ У МЛАДШИХ ШКОЛЬНИКОВ С НАРУШЕНИЕМ РЕЧ ${ }^{1}$
}

\section{ORGANIZATION AND RESULTS OF THE STUDY OF THE LEVEL OF DEVELOPMENT OF FINE MOTOR SKILLS IN PRIMARY SCHOOLCHILDREN WITH SPEECH IMPAIRMENT}

\section{Abramova}

V. Larina

Summary: This article is devoted to the problem of studying the level of development of fine motor skills in primary schoolchildren with speech impairment. The paper presents the methodology and results of an experimental study of this aspect and outlines the organizational and substantive foundations of the correctional and pedagogical activity of a speech therapist for the development of fine motor skills in junior schoolchildren with speech impairment by means of finger gymnastics.

Keywords: finger motor skills, development, speech impairment.

\author{
Абрамова Инна Викторовна \\ К.п.н., дочент, Мордовский государственный \\ педагогический университет имени М.Е. Евсевьева \\ (2. Саранск) \\ iva-76@yandex.ru \\ Ларина Виктория Дмитриевна \\ Мордовский государственный педагогический \\ университет имени М.Е. Евсевьева (2. Саранск) \\ victoriialarina@gmail.com
}

Аннотация: Настоящая статья посвящена проблеме исследования уровня развития мелкой моторики у младших школьников с нарушением речи. $\mathrm{B}$ работе представлены методика и результаты экспериментального исследования указанного аспекта и обозначены организационно-содержательные основы коррекционно-педагогической деятельности логопеда по развитию мелкой моторики у младших школьников с нарушением речи средствами пальчиковой гимнастики.

Ключевые слова: мелкая моторика, развитие, нарушение речи. $\mathrm{y}$ спешное вхождение в общество подрастающего поколения во многом зависит от степени освоения им накопленного опыта, отраженного в образовательных программах разного уровня. Поэтому задача современной образовательной организации - создать все необходимые условия для полноценного освоения этого ресурса. Одним из таких условий является логопедическое сопровождение детей, имеющих нарушение речи $[1 ; 2 ; 5]$.

У детей рассматриваемой категории недостаточно развита мелкая моторика. Это проявляется в ощущении дискомфорта в мышцах доминантной руки, затекании кисти и пальцев, онемении или дрожании руки, что приводит к написанию вибрирующих линий букв. В задачи логопеда входит развитие мелкой моторики рук у младших школьников, имеющих нарушение речи, это обусловлено тесным взаимодействием ручной и речевой моторики. Поэтому в рамках экспериментального исследования, целью которого было определено совер- шенствование коррекционно-педагогической деятельности логопеда по развитию мелкой моторики младших школьников с нарушением речи, возникла необходимость целенаправленного изучения уровня развития мелкой моторики у детей младшего школьного возраста.

Экспериментальное исследование проводилось на базе Ялгинской средней общеобразовательной школы г. о. Саранск, участниками были 11 обучающихся младших классов в возрасте от 7 до 8 лет, с речевыми нарушениями (общее недоразвитие речи III уровня).

При разработке методики констатирующего эксперимента учитывались исследования А.Р. Лурии о высших корковых функциях человека и их нарушениях при локальных поражениях мозга [3], их обобщения, представленные Т.В. Ахутиной, Н.Н. Полонской, Н.М. Пылаевой, Л.В. Яблоковой в формате методов нейропсихологического обследования детей 6-8 лет [7], и рекомендации к оценке психолого-педагогической готовности ребенка к

Исследование выполнено в рамках гранта на проведение научно-исследовательских работ по приоритетным направлениям научной деятельности вузов-партнеров по сетевому взаимодействию (Южно-Уральский государственный гуманитарнопедагогический университет и Мордовский государственный педагогический университет имени М.Е. Евсевьева) по теме: «Проектирование коррекционно-педагогической деятельности логопеда в условиях инклюзивной практики». 
школе, предложенные Н.В. Нижегородцевой и В.Д. Шадриковым [4].

Для диагностики мелкой моторики мы выбрали следующие критерии ее развития:

1. развитие точности движений,

2. развитие ловкости пальцев,

3. развитие силы кисти и выносливости пальцев.

Диагностическая проба № 1. «Ребро - ладонь - кулак».

Цель: в данной методике оценивается умение ребенка точно выполнить движение.

Ребенку показывают три положения руки на плоскости стола, последовательно сменяющих друг друга. Ладонь на плоскости, ладонь, сжатая в кулак, ладонь ребром на плоскости стола, распрямленная ладонь на плоскости стола. Ребенок выполняет пробу вместе с педагогом, затем по памяти в течение 8-10 повторений моторной программы. Проба выполняется сначала правой рукой, затем - левой, затем - двумя руками вместе.

Инструкция: «Посмотри внимательно и сделай, как я. Делай до тех пор, пока я тебя не остановлю». Если ребенок не может повторить движения после показа, повторный показ сопровождается следующей инструкцией: «Положи обе руки на стол - вот так. Одну сожми в кулак, а другая пусть пока лежит спокойно. Теперь положи руки вот так. Продолжай вместе со мной».

Критерии оценивания выполнения диагностической пробы:

1. сформирован в достаточной мере - ребенок выполняет задание самостоятельно под словесное сопровождение взрослого,

2. сформирован в не достаточной мере - ребенок затрудняется выполнить самостоятельно, требуется показ взрослого,

3. не сформирован - ребенок затрудняется в выполнении движений самостоятельно и по показу, требуется помощь взрослого (педагог придерживает руки ребенка).

Диагностическая проба № 2. «Бусы в подарок маме».

Цель: методика направлена на оценку точности действий и ловкость пальцев. Оборудование: бусины 2,5 сантиметра, шнурок с узлом на одном конце.

Дети нанизывают круглые пластмассовые шары с отверстием диаметром 2,5 сантиметра на шнурок со стопором на одном конце.

Инструкция: «Посмотри, у нас есть бусины и шнурок.
Тебе необходимо сделать так, чтобы все бусины были нанизаны на шнурок».

Критерии оценивания выполнения диагностической пробы:

1. Сформирован в достаточной мере - ребенок выполняет задание самостоятельно, без помощи и показа взрослого, четко попадая в отверстия, не теряя бусины или шнурок.

2. Сформирован в не достаточной мере - ребенок выполняет задание после показа взрослым.

3. Не сформирован - ребенок затрудняется в выполнении задания самостоятельно, ему требуется помощь взрослого.

Диагностическая проба № 3. «Дорожки».

Цель: при проведении данной методика оценивается сила, с которой дети рисовали, т. е. сильный или слабый нажим руки на карандаш.

Оборудование: карточки с «дорожками», карточки с пунктирными линиями, карандаш.

Умение проводить горизонтальные и вертикальные линии. Детям предлагают карточки, где нужно провести линию по дорожке, так же по пунктирной линии.

Инструкция: «Здесь нарисованы разные персонажи и дорожки к домикам. Ты должен соединить линией персонажа с домиком, не съезжая с дорожки».

Критерии оценивания выполнения диагностической пробы:

1. Сформирован в достаточной мере - все линии ровные, четкие, примерно одинаковой длины.

2. Сформирован в недостаточной мере - линии разной длины, не четкие, не достаточно ровные: под наклоном, прерывистые.

3. Не сформирован - ребенок затрудняется в выполнении задания.

Диагностическая проба № 4 «Спрячь мышку».

Цель: оценить умение ребенка закрашивать изображение карандашом, затрачивая при этом достаточно времени и сил, выносливость.

Оборудование: карточки с изображением, карандаш.

Штриховка изображения карандашом. Детям предлагается изображение персонажа, которого нужно спрятать, заштриховав полностью.

Инструкция: «Посмотри на рисунок. Это мышка и за ней гонится кошка, которая хочет ее съесть. Давай спрячем мышку, для этого тебе нужно ее заштриховать так, 
что ее не было видно».

Критерии оценивания выполнения диагностической пробы:

1. сформирован в достаточной мере - ребенок штрихует все изображение;

2. сформирован в не достаточной мере - ребенок штрихует больше половины изображения;

3. не сформирован - ребенок штрихует менее половины изображения.

Диагностика проходила по следующему алгоритму. Первоначально беседовали с ребенком: узнавали, как его зовут, сколько ему лет, любит ли он рисовать, занимается ли где в кружках, где может развиваться мелкая моторика, например: художественная школа, кружки вязания, плетения. Затем проводилась непосредственно диагностика - индивидуально в игровой форме. Результаты фиксировались по ходу выполнения задания.

Критерии диагностики мы выделили следующие: развитие точности движений, развитие ловкости пальцев и развитие силы кисти и выносливости пальцев.

Уровень развития точности движений мы оцениваем по результатам первой методики «Ребро - ладонь - кулак». После выполнения мы получили такие результаты. Задание выполняли 11 детей (100\%). Из них у 73 \% данный навык сформирован в достаточной мере - они самостоятельно, под диктовку смогли воспроизвести все нужные действия и у 27 \% наблюдались явные ошибки, что позволило нам сделать вывод о недостаточно сформированном навыке. Были допущены ошибки в последовательности движений. Дети путали последовательность или пропускали некоторые из них, делали большие паузы между элементами, вспоминая следующее движение, могли несколько раз повторить один и тот же элемент. Таким образом, мы можем сделать вывод, что уровень развития точных движений сформирован у $73 \%$ детей и лишь у $27 \%$ он сформирован в недостаточной мере.

Уровень развития ловкости движений мы оценивали по второй методике «Бусы в подарок маме», результаты проведения задания оказались следующими. У $36 \%$ детей данный критерий сформирован в достаточной мере - они смогли выполнить задание самостоятельно, без помощи и показа взрослого, четко попадая в отверстия, не теряя бусины или шнурок. У 64\% навык сформирован в не достаточной мере - при выполнении задания теряли бусины, выпускали из пальцев шнурок или не доводили бусины до его конца, некоторые надевали не все бусины.

Исходя из этого, мы сделали вывод, что только у $36 \%$ детей уровень развития ловкости достаточно сформирован, остальные 64\% - это дети с недостаточным уров- нем сформированности данного критерия.

Далее мы оценивали уровень развития силы кисти и выносливости пальцев. Делали мы это при помощи следующих методик: «Дорожки» и «Спрячь мышку». Результаты первой методики оказались следующими: все дети выполнили задание. Однако только у 3 линии были аккуратные и проведены строго по пунктиру, еще 1 ученик так же провел ровно и аккуратно, но не доводил линии до конца и начинал не с самого начала рисунка. Самой большой группой - 7 человек стали дети, которые провели линии нечетко, выходя за границы пунктирной строки, или в каких-то места, не касаясь ее совсем. Исходя из этого, 36\% показали достаточный уровень сформированности, а 64\% - недостаточный.

При проведении методики «Спрячь мышку» мы получили следующие результаты. С данным заданием справилось все дети. Полностью заштриховали рисунок 3 школьника, оставили пустые места 7 человек, оставил пустой наполовину - 1 ребенок. Сила нажатия тоже была различной, первая группа (3 человека) не меняла силу нажимы на протяжении всей штриховки, вторая (8 человек) начала штриховать достаточно сильно, но под конец нажим ослаб, расстояние между штрихами увеличилось. Так же они начинали штриховку интенсивно, но к середине рисунка скорость замедлялась.

Исходя из данных результатов, мы можем сделать следующий вывод: у 64\% данный критерий недостаточно сформирован, оставшиеся 36\% показали хороший уровень.

Таким образом, диагностика показала, что более чем у $60 \%$ уровень основных показателей уровня развития мелкой моторики сформирован в несоответствии с возрастной нормой, наблюдается неточность и неполнота действий, дети не выполняют задания полностью, какието задания не могут выполнить без взрослого, им сложно проводить линии по пунктиру, полностью заштриховать рисунок или продеть шнурок во все шарики, не роняя его и не теряя бусин.

А так как на логопедических занятиях не всегда отводится достаточно времени на развитие мелкой моторики, мы разработали ряд рекомендаций, которые позволят развивать мелкую моторику не только на логопедических занятиях, но и на таких занятиях, как изобразительное искусство и технология.

Работа с пластилином или лепка - хороший способ не только занять развлечь ребенка, но и развить мелкую моторику рук. Ребенок так развивает в это момент и эстетически, усваивает культуру и узнает ее особенности. Создавая своими руками фигурки из пластилина, ребенок приучается к трудовой деятельности, у него приходят в 
тонус мышцы пальцев, развивается их выносливость. Так же тренируется усидчивость и внимательность ребенка. Так как моторные области речи и движений рук находятся рядом, параллельно идет и активизация развития речевой деятельности. Для того что бы ребенку н наскучило это занятия и он развивался, необходимо постоянно обновлять материал, усложнять его по мере усвоения. При работе с пластилином дети осваивают различные техники, которые позволяют, раскатывая, защипывая, сплющивая, развивать мелкую моторику.

Так же можно использовать графические задания, помимо того, что, благодаря этим занятиям будет совершенствоваться линии букв ребенка, так же будет развиваться зрительная память, профилактика оптической дисграфии. Рекомендуется так использовать различные карточки и каллиграфические прописи, которые позволят ребенку интересно усваивать материал.

Так, можно привести в пример Су-Джок - массажер в виде массажных шариков, в комплекте с массажными металлическими колечками. Шариком можно стимулировать зоны на ладонях, а массажные кольца надеваются на пальчики.

Методов развития мелкой моторики у младших школьников с нарушением речи достаточно много, но нельзя не упомянуть пальчиковую гимнастику. Пальчиковая гимнастика - это инсценировка стихов или каких-либо историй при помощи пальцев. Она не требует сложной подготовки, дополнительных тренажёров и пособий, доступна для проведения как на логопедических занятиях, таких на уроках и даже дома. Поэтом мы можем рекомендовать ее для занятий по развитию мелкой моторики, а так как в процессе занятия используется текстовый материал, она так же будет актуальна и для развития и коррекции речи.

На основе пособия В.В. Цвынтарного «Играем пальчиками и развиваем речь» [6] был разработан комплекс упражнений, включающих схематичное изображение движения рук с инструкцией, текстовый материал и наглядный материал. Комплекс включает три раздела. Первый направлен на развитие точности движений. В него входят следующие упражнения: «Кораблик», «Страус», «Бабочка». Второй раздел направлен на развитие ловкости пальцев. Для этого в комплекс входят упражнения:
«Ножницы», «Лось», «Гриб». За развитие силы кисти и выносливости пальцев отвечает третий раздел - упражнения: «Телевизор», «Улитка», «Книга». Упражнение «Улитка» подходит под все три раздела. Данный комплекс упражнений, рассчитан на младших школьников с нарушением речи, представленные упражнения способствуют развитию мелкой моторики, расширению кругозора и развитию речи. На наш взгляд, данный комплекс удобен в использовании, как педагогами, так и родителями. Приведем пример экспериментального упражнения (рисунок 1).

Упражнение «Паук»

Чем же занят в паутине этот милый паучок? Он уже расставил сети и пустился наутек.

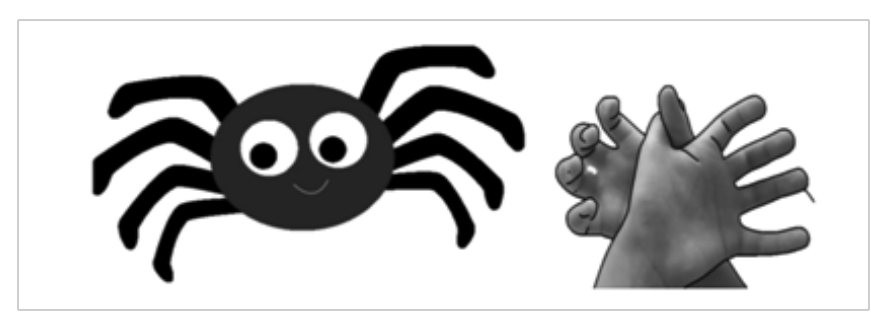

Рис. 1. Упражнение «Паук»

Инструкция: расслабьте кисти рук, положите одну на другую, ладонями вверх - крест-накрест, соедините большие пальцы.

Далее мы разработали в соответствии с календарным планом работы логопеда образовательной организации тематическое планирование. В нем отражены темы занятий, количество часов, упражнения из комплекса, которые мы использовали. Комплекс упражнений по развитию мелкой моторики включен в каждое логопедическое занятие отдельным блоком упражнений - 3 упражнения, которые будут постепенно сменяться от простых к более сложным.

Можно утверждать, что коррекционно-развивающая работа на логопедических занятиях с использованием таких методов, как активная и пассивная пальчиковая гимнастика, пальчиковые упражнения активизирует не только речевую, но и мыслительную деятельность младших школьников с нарушением речи. У них наблюдается заметная положительная динамика развития мелкой моторики, что подтверждено результатами контрольного эксперимента.

\section{ЛИТЕРАТУРА}

1. Абрамова, И.В. Организационно-содержательные основы деятельности педагога по обеспечению единого речевого режима для обучающихся с речевыми нарушениями / И.В. Абрамова, И.В. Лапшина, Н.П. Милованцева. // Современная наука: актуальные проблемы теории и практики. - $2019 .-$ № 12 (2). - C. 74-78.

2. Логопедия. Теория и практика / под ред. Т.Б. Филичевой. - М.: Эксмо, 2017. - 608 с. 
3. Лурия, А.Р. Высшие корковые функции человека и их нарушения при локальных поражениях мозга / А.Р. Лурия. - М.: Издательство московского университета, 1962. -432 c.

4. Нижегородцева, Н.В. Психолого-педагогическая готовность ребенка к школе: пособие / Н.В. Нижегородцева, В.Д. Шадриков. - М.: ВЛАДОС, 2001. - 256 С.

5. Основы логопедической работы с детьми: учебное пособие / под общ.ред. Г.В. Чиркиной. - М.: АРКТИ, 2011. - 240 с.

6. Ц Цвынтарный, В.В. Играем пальчиками - развиваем речь: пособие / В.В. Цвынтарный. - М.: Академия, 2012. - 132 с.

7. Яблокова, Л.В. Методы нейропсихологического обследования детей 6-8 лет / Н.М. Пылаева, Т.В. Ахутина, Н.Н. Полонская, Л.В. Яблокова // Вестник Московского университета. - Серия 14. Психология. - 1996 - № 2. - URL: http://childpsy.ru/lib/articles/id/9679.php.

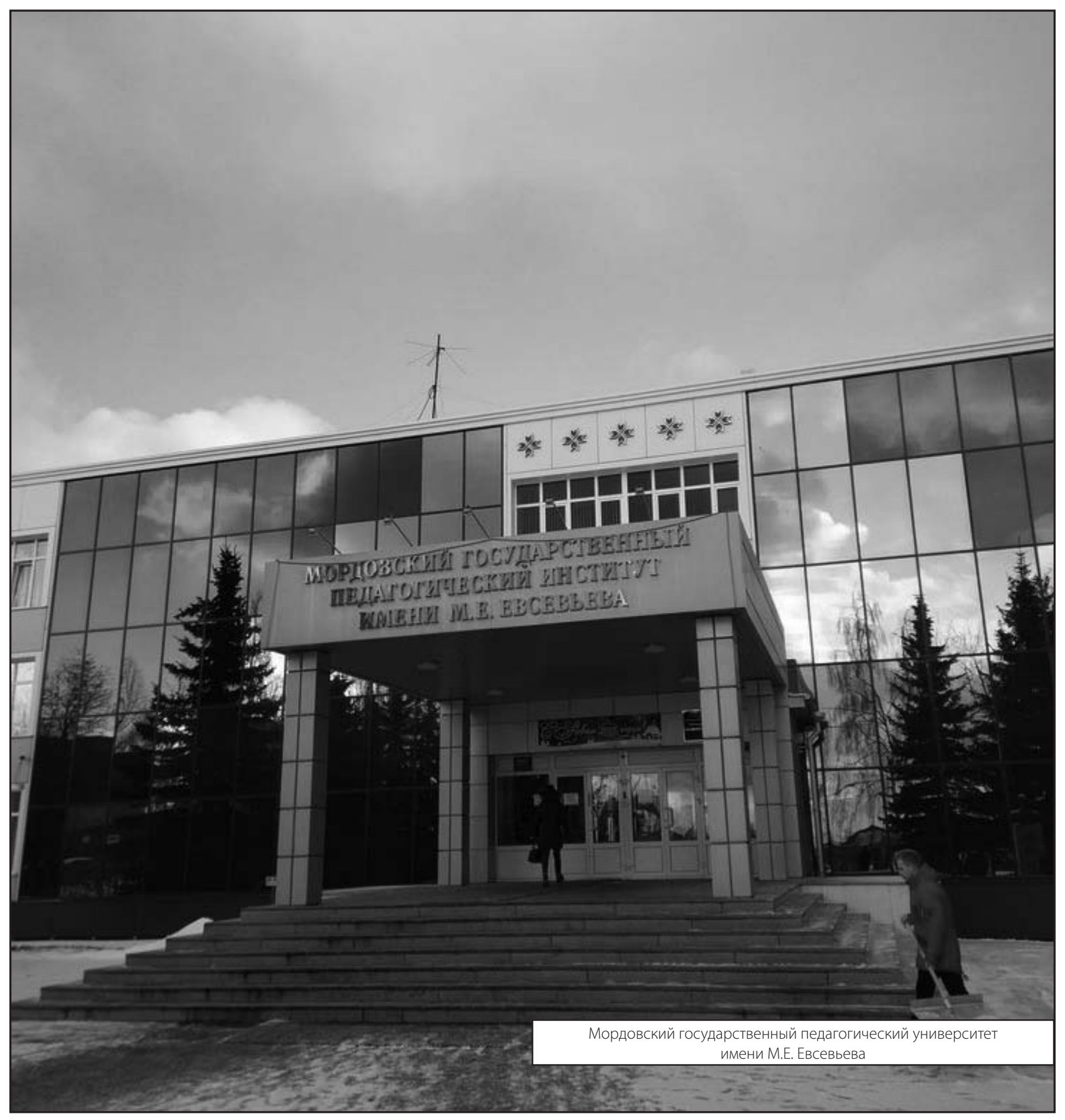

